\title{
Sequential changes in ovarian follicular dynamics in Bos indicus heifers before and after nutritional anoestrus
}

\author{
F. M. Rhodes, L. A. Fitzpatrick, K. W. Entwistle* and G. De'ath \\ Department of Biomedical and Tropical Veterinary Sciences, James Cook University of North Queensland, \\ Townsville, Q4811, Australia
}

This study examined the effects of live mass on ovarian follicular dynamics in heifers before and after the onset of nutritional anoestrus. The effects of decreased live mass on secretion of progesterone, LH and FSH were also investigated. Ovarian characteristics were monitored in 16 postpubertal Brahman heifers using daily transrectal ultrasonography. After two normal oestrous cycles, 11 heifers (treatment group) were allocated to a restricted diet, until the cessation of their oestrous cycles, that resulted in a decrease in live mass of $0.8 \mathrm{~kg}$ day $^{-1}$. Heifers were then fed an ad libitum diet, resulting in increasing live mass until resumption of oestrous cycles. Five heifers (control group) were fed an unrestricted diet throughout the experimental period. The concentrations of progesterone in plasma were monitored twice a week and the concentrations of LH and FSH were determined on day 6 after ovulation, before initiation of dietary restriction, after a $17 \%$ decrease in live mass and after the onset of anoestrus in the treatment group. Onset of anoestrus was preceded by linear decreases in the size of ovarian follicles and corpora lutea, and in the persistence of the first dominant follicles of oestrous cycles. These changes were proportional to the decrease in live mass $(P<0.001)$. The frequency of pulses of LH or mean concentration of FSH on day 6 of the oestrous cycle were not changed after a $17 \%$ decrease in live mass, and did not increase following the onset of anoestrus, although concentrations of progesterone were $<0.2 \mathrm{ng} \mathrm{ml}^{-1}$, suggesting that release of LH was suppressed at this time. Increasing live mass following anoestrus resulted in a linear increase in dominant follicle size and persistence, which were correlated with changing mass $(P<0.001)$; ovulation resumed when dominant follicles were $105 \pm 4 \%$ of the size of initial ovulatory follicles.

\section{Introduction}

In northern Australia, as is the case in most tropical and subtropical environments, the available nutrient supply varies considerably with season of year such that during the dry season there is often an inadequate supply of forage to meet the maintenance requirements of grazing cattle. Body mass and body condition therefore undergo oscillating patterns of increase during the wet season and decrease during the dry season (Holroyd et al., 1979). The severity of weight loss and decrease in condition have major effects on reproductive performance, with degree of weight loss during the preceding dry season and condition at mating correlating with conception rates in both heifers and mature cows (Doogan et al., 1991; O'Rourke et al., 1991).

For successful mating to occur, a sequence of coordinated endocrinological events must culminate in display of behavioural oestrus and ovulation of an ovarian follicle. Restricted dietary intake reduces the size of dominant ovarian follicles in pre- and postpubertal heifers (Murphy et al., 1991; Bergfeld

*Present address: Faculty of the Sciences, The University of New England, Armidale, NSW 2351, Australia.

Received 30 September 1994 et al., 1994) and delays the development of large follicles in postpartum cows (Ryan et al., 1994). Decreased dietary energy intake is also associated with decreased pulsatile secretion of LH in pre- and postpubertal heifers and mature cows (Imakawa et al., 1986a; Richards et al., 1989; Kurz et al., 1990), while extended periods of dietary restriction result in the cessation of oestrous cycles (Imakawa et al., 1986b; Richards et al., 1989). However, the sequential changes in ovarian follicular dynamics during such nutritional restriction events have not been reported.

The objectives of this study were (i) to characterize changes in ovarian morphology in Bos indicus heifers with decreasing live mass until the cessation of oestrous cycles, and to determine whether these changes were associated with changes in secretion of progesterone, $\mathrm{LH}$ and $\mathrm{FSH}$, and (ii) to examine the pattern of follicular dynamics with increasing live mass, until the resumption of oestrous cycles.

\section{Materials and Methods}

\section{Animals and procedures}

The study was performed at James Cook University, Townsville (latitude $19^{\circ} 19^{\prime} \mathrm{S}$; longitude $146^{\circ} 43^{\prime} \mathrm{E}$ ) in the dry 
tropics of North Queensland. The climate is generally warm and humid, having a distinct hot, wet summer period (October to April) and a warm dry winter period (May to September). During the experimental period, mean monthly minimum and maximum temperatures ranged between $24^{\circ} \mathrm{C}$ and $31^{\circ} \mathrm{C}$ in February and between $15^{\circ} \mathrm{C}$ and $26^{\circ} \mathrm{C}$ in August.

A group of 16 postpubertal Brahman heifers were studied for 10 months between August and June. At the start of the study they were 18 months old, body mass was $307.0 \pm 3.0 \mathrm{~kg}$ (mean \pm SEM) and they had a condition score of $5.7 \pm 0.08$ ( $1=$ emaciated and $9=$ fat; Holroyd, 1978). At the start of the experimental period, all heifers were allowed sorghum hay ad libitum (dry matter digestibility $53 \%$, crude protein content $56.3 \mathrm{~g} \mathrm{~kg}^{-1}$ and estimated dry matter metabolizable energy $8.4 \mathrm{MJ} \mathrm{kg}^{-1}$ ). In addition, they had access to native pasture and an $8 \%$ urea-molasses supplement (crude protein content $349 \mathrm{~g}$ $\mathrm{kg}^{-1}$ and estimated dry matter metabolizable energy $10.7 \mathrm{MJ}$ $\mathrm{kg}^{-1}$ ). After observation of two interovulatory intervals, of mean duration $21.4 \pm 0.83$ days, 11 heifers (treatment group) were allocated to a restricted diet, with a daily dry matter intake of $0.5 \%$ of live mass. Heifers were fed reduced quantities of hay, with $60 \mathrm{~g}$ per heifer day ${ }^{-1}$ of a dry-mix mineral supplement, which resulted in an average daily decrease in live mass of $0.8 \pm 0.05 \mathrm{~kg}$ until onset of anoestrus (period of decreasing live mass). Feeding of the restricted diet continued for a further 21 days and then heifers were returned to the original unrestricted diet until an interovulatory interval of $\geq 17$ days was recorded (period of increasing live mass). Five heifers (control group) remained on the initial diet throughout the experimental period, which resulted in an average daily gain in live mass of $0.5 \pm 0.06 \mathrm{~kg}$. All animals were weighed twice a week and condition scores were recorded each week.

\section{Ultrasonography}

The ovaries of all heifers were examined daily, between 07:00 $\mathrm{h}$ and $08: 00 \mathrm{~h}$, using transrectal ultrasonography (7.5 MHz transducer, Aloka 210DX). No attempt was made to synchronize the stage of oestrous cycles during the period of the experiment. The size and position of corpora lutea and all follicles $\geq 5 \mathrm{~mm}$ in diameter were recorded as described by Savio et al. (1988). Ovulation was determined by the disappearance of a dominant follicle and subsequent formation of a corpus luteum in the same location on the ovary. The day of ovulation was defined as day 0 and the duration of oestrous cycles as the interval between two successive ovulations. Anoestrus was defined as failure of ovulation of a dominant follicle following luteolysis. The following variables were also defined: persistence of follicles or corpora lutea as the number of days when individual follicles or corpora lutea $\geq 5 \mathrm{~mm}$ were detected; maximum diameter as the largest diameter measured in dominant follicles or corpora lutea; growth rate $\left(\mathrm{mm}^{\mathrm{day}}{ }^{-1}\right.$ ) of follicles as the maximum diameter minus the diameter on the day of detection divided by the interval in days.

\section{Collection of blood samples}

Concentrations of progesterone in plasma were monitored twice a week in jugular blood samples. Serial blood samples were collected via indwelling jugular catheters on three occasions from all heifers during the course of the experiment. During the second oestrous cycle, before initiation of dietary restriction, blood samples $(10 \mathrm{ml}$ ) were collected every $15 \mathrm{~min}$ for $8 \mathrm{~h}$ (sampling period 1 ). When the treatment heifers had lost approximately $15 \%$ of their initial live mass $(7.1 \pm 1.8$ weeks after the start of dietary restriction), blood samples were collected every $15 \mathrm{~min}$ for $10 \mathrm{~h}$ (sampling period 2). After the onset of anoestrus in treated heifers, before they were re-allocated to ad libitum dietary intake, samples were again collected every $15 \mathrm{~min}$ for $10 \mathrm{~h}$ (sampling period 3). On all occasions, except when treated heifers were in anoestrus, samples were collected on day 6 of the oestrous cycle, when the first dominant follicle was still increasing in size. After collection, blood samples were immediately placed on ice; plasma was separated by centrifugation at $3000 \mathrm{~g}$ within $1 \mathrm{~h}$ and then stored at $-20^{\circ} \mathrm{C}$ until assayed. Concentrations of $\mathrm{LH}$ were determined in all plasma samples and concentrations of FSH were measured in pooled hourly samples.

\section{Radioimmunoassays}

Concentrations of progesterone in plasma were determined using a modification of the Danazol method (McGinley and Casey, 1979) described by Jolly (1992). The intra- and interassay coefficients of variation (CVs) at the approximate midpoint of the standard curve $\left(1.0 \mathrm{ng} \mathrm{ml}^{-1}\right)$ were $8.8 \%$ and $9.1 \%$, respectively, and the sensitivity of the assay, as defined by the concentration at $90 \%$ of maximum binding, was $0.03 \mathrm{ng} \mathrm{ml}^{-1}$.

Concentrations of $\mathrm{LH}$ in plasma were measured by doubleantibody radioimmunoassay, using a modification of the method described by Niswender et al. (1969). Purified bovine LH (USDA-bLH-B-6, AFP-11743-B) was provided by D. Bolt (USDA Animal Hormone Program, Beltsville, MD). The antiserum used was NIDDK-anti-oLH-1 (AFP-192279), which was supplied by NIDDK, Bethesda, MD. Iodination of bLH was performed using a modification of the chloramine- $T$ method described by Bolt and Rollins (1983). All assay reagents were prepared in $0.04 \mathrm{~mol}$ phosphate buffered saline $1^{-1}(\mathrm{pH}$ 7.2) containing $50 \mathrm{mg}$ egg albumin $\mathrm{ml}^{-1}$ (RIAD, McNeilly et al., 1976). Duplicate $100 \mu \mathrm{l}$ aliquots of standards or samples were incubated with $50 \mu \mathrm{l}$ of normal rabbit serum (diluted 1:250 in RIAD), $50 \mu \mathrm{l}$ of antiserum (1:400 000 dilution in RIAD) and $50 \mu \mathrm{l}$ of tracer (12000 c.p.m.) for $24 \mathrm{~h}$. Donkey anti-rabbit serum ( $50 \mu \mathrm{l}$; IDS, Boldon, Tyne and Wear), diluted 1:25 in RIAD, was then added and the tubes were incubated for $18 \mathrm{~h}$ at $4^{\circ} \mathrm{C}$. After addition of $300 \mu \mathrm{l}$ of RIAD, the tubes were centrifuged at $3000 \mathrm{~g}$ for $30 \mathrm{~min}$ at $4^{\circ} \mathrm{C}$. Supernatants were decanted and the radioactivity of the pellet counted. Increasing volumes $(3.125-100 \mu \mathrm{l})$ of plasma in three pools produced displacement of radioligand that paralleled the standard curve. Quantitative recovery of added $\mathrm{LH}$ was evaluated by adding 0 , $0.31,0.63,1.25,2.50$ and $5.0 \mathrm{ng}$ of USDA-bLH-B-6 to three plasma pools. There was a linear relationship between the concentrations of $\mathrm{LH}$ recovered and $\mathrm{LH}$ added $\left(R^{2}=0.94\right)$. The interassay CVs for two bovine plasma pools of 0.28 and $1.82 \mathrm{ng} \mathrm{ml}^{-1}$ were 19.7 and $6.3 \%$, respectively. The intraassay CVs for the same plasma pools were 15.0 and $5.9 \%$, respectively. Assay sensitivity, defined as the concentration at $90 \%$ of maximum binding, was $0.15 \mathrm{ng} \mathrm{ml}^{-1}$. 
Plasma concentrations of FSH were measured by doubleantibody radioimmunoassay, using a modification of the method described by Bolt and Rollins (1983). Purified bovine FSH (USDA-bFSH-I-2, AFP-5318C) was provided by D. Bolt, USDA Animal Hormone Program. The antiserum used was NIDDK-anti-oFSH-1 (AFP-C5288113; NIDDK). Iodination of bFSH was performed using a modification of the chloramine- $T$ method described by Bolt and Rollins (1983). Duplicate $100 \mu \mathrm{l}$ aliquots of standards or samples were preincubated with $400 \mu \mathrm{l}$ RIAD and $200 \mu \mathrm{l}$ of antiserum diluted 1:50 000 with RIAD containing 1:300 normal rabbit serum, for $24 \mathrm{~h}$ at room temperature. Iodinated tracer $(100 \mu \mathrm{l})$, with an activity of about 15000 c.p.m., was added and the incubation continued for a further $48 \mathrm{~h}$. Donkey anti-rabbit serum $(200 \mu \mathrm{l})$, diluted 1:25 in RIAD, was then added with $500 \mu \mathrm{l}$ of $6 \%(\mathrm{w} / \mathrm{v})$ polyethylene glycol $(6 \mathrm{kDa})$ in RIAD. The tubes were incubated for $15 \mathrm{~min}$ at $4^{\circ} \mathrm{C}$ before centrifugation at $3000 \mathrm{~g}$ for $20 \mathrm{~min}$ at $4^{\circ} \mathrm{C}$. The supernatant was decanted and the tubes drained for at least 10 min before the amount of radioactivity was determined. Parallel inhibition of tracer binding by FSH in plasma samples and USDA bFSH standard was determined using two plasma pools serially diluted 1:1 to 1:32 with assay buffer. Displacement curve slopes of sample pools and assay standards were similar when compared using analysis of covariance $(P=0.169)$. Quantitative recovery of added FSH was evaluated by adding $0,0.16,0.32,0.64,1.28,2.56$ and $5.12 \mathrm{ng}$ of USDA-bFSH-I-2 to $0.5 \mathrm{ml}$ of each of three plasma pools. There was a linear relationship between the concentrations of FSH recovered and FSH added $\left(R^{2}=0.99\right)$. The interassay $C V s$ for two bovine plasma pools of 0.24 and $3.54 \mathrm{ng} \mathrm{ml}^{-1}$ were 10.7 and $7.1 \%$, respectively. The intra-assay $\mathrm{CVs}$ for the same plasma pools were 9.0 and $5.2 \%$, respectively. Assay sensitivity, defined as the concentration at $90 \%$ of maximum binding, was $0.12 \mathrm{ng} \mathrm{ml}^{-1}$.

\section{Statistical analyses}

The rates of change of variables with the number of oestrous cycles during the period of decreasing live mass were examined using a linear model with an autoregressive error structure (Jennrich and Schluchter, 1986). The last oestrous cycle before the initiation of dietary restriction in treatment heifers was defined as oestrous cycle 0 and all cycles until the onset of anoestrus were included. The rates of change for treatment and control groups were estimated for each variable. The same model was used to examine the rates of change of variables with the dominant follicle number during the period of increasing live mass following anoestrus. The relationships between live mass and ovarian characteristics in treatment heifers were examined using multiple regression analysis. The mean rates of change were estimated using a random coefficients linear model (Lindsey, 1993). Results from these analyses are presented as least squares estimates together with standard errors.

The mean concentration, basal concentration, pulse frequency and pulse amplitude of LH during the three periods of serial blood collection were determined using a modified version of the algorithm developed by Merriam and Wachter (1982) and adapted for IBM-compatible personal computers (PULSAR: R. Lazarus, Department of Community Medicine,
Westmead Hospital, NSW). The ' $G$ ' parameters used were those derived empirically for $\mathrm{LH}$ profiles by Merriam and Wachter (1982), namely 3.8, 2.6, 1.9, 1.5 and 1.2 for $G(1)$ to $G(5)$, respectively. Differences in pulsatile secretion of LH and mean concentration of FSH between the different sampling periods were examined using multivariate repeated measures analysis of variance. The changes in differences between control and treated heifers from periods 1 to 2 and from periods 1 to 3 were evaluated as pre-planned contrasts.

The timing of onset of anoestrus in treated heifers was modelled using logistic regression. All explanatory variables were expressed as proportions of their values before the initiation of restriction of dietary intake. A subset of significant explanatory variables was determined using backward elimination of non-significant variables $(P>0.05)$, based on the likelihood-ratio test (Collett, 1991).

Repeated measures analysis of variance was used to compare the ovarian characteristics of oestrous cycles before dietary restriction in treated heifers with the first oestrous cycle of normal duration after the resumption of ovulation, and with oestrous cycles of control heifers occurring at a similar time.

The MIXED procedure in SAS (1992) was used for the autoregressive linear model. For all other statistical analyses, SPSS (1993) was used.

\section{Results}

\section{Period of decreasing live mass}

Linear decreases in the live mass, condition score, maximum diameter of the first dominant follicles of oestrous cycles, ovulatory follicles and corpora lutea and the persistence of the first dominant follicles were observed in the treatment group, when all oestrous cycles before the onset of anoestrus were considered $(P<0.01$, Figs 1 and 2$)$. During the same period in the control group, there were linear increases in the live mass, condition score $(P<0.001)$, size $(P<0.01)$ and growth rate $(P=0.02)$ of ovulatory follicles (Figs $I$ and 2$)$. There was no change in the persistence of corpora lutea or in the mean concentrations of progesterone in either treatment or control groups during this period $(P>0.1)$. The number of dominant follicles per oestrous cycle did not change over the period of decreasing live mass in treatment heifers $(P=0.30)$ or in control heifers over the same time $(P=0.98)$. Changing live mass in treated heifers was linearly associated with changes in ovarian characteristics $(P<0.001)$. For every $10 \mathrm{~kg}$ decrease in live mass, the maximum diameter of the first dominant follicles of oestrous cycles decreased by an estimated $0.31 \pm 0.005 \mathrm{~mm}$; persistence of the first dominant follicles decreased by $0.39 \pm 0.018$ days; ovulatory follicle size decreased by $0.31 \pm 0.006 \mathrm{~mm}$ and the maximum diameter of corpora lutea decreased by $0.64 \pm 0.018 \mathrm{~mm}$. There were also linear relationships between live mass and ovarian characteristics, when expressed as proportions of values before the initiation of dietary restriction $(P<0.001)$. A $10 \%$ decrease in live mass resulted in an estimated $9.4 \pm 0.7 \%$ decrease in the maximum diameter of first dominant follicles of oestrous cycles, an $8.5 \pm 0.8 \%$ decrease in ovulatory follicle size and a $10.6 \pm 0.9 \%$ decrease in the maximum diameter of corpora lutea. 

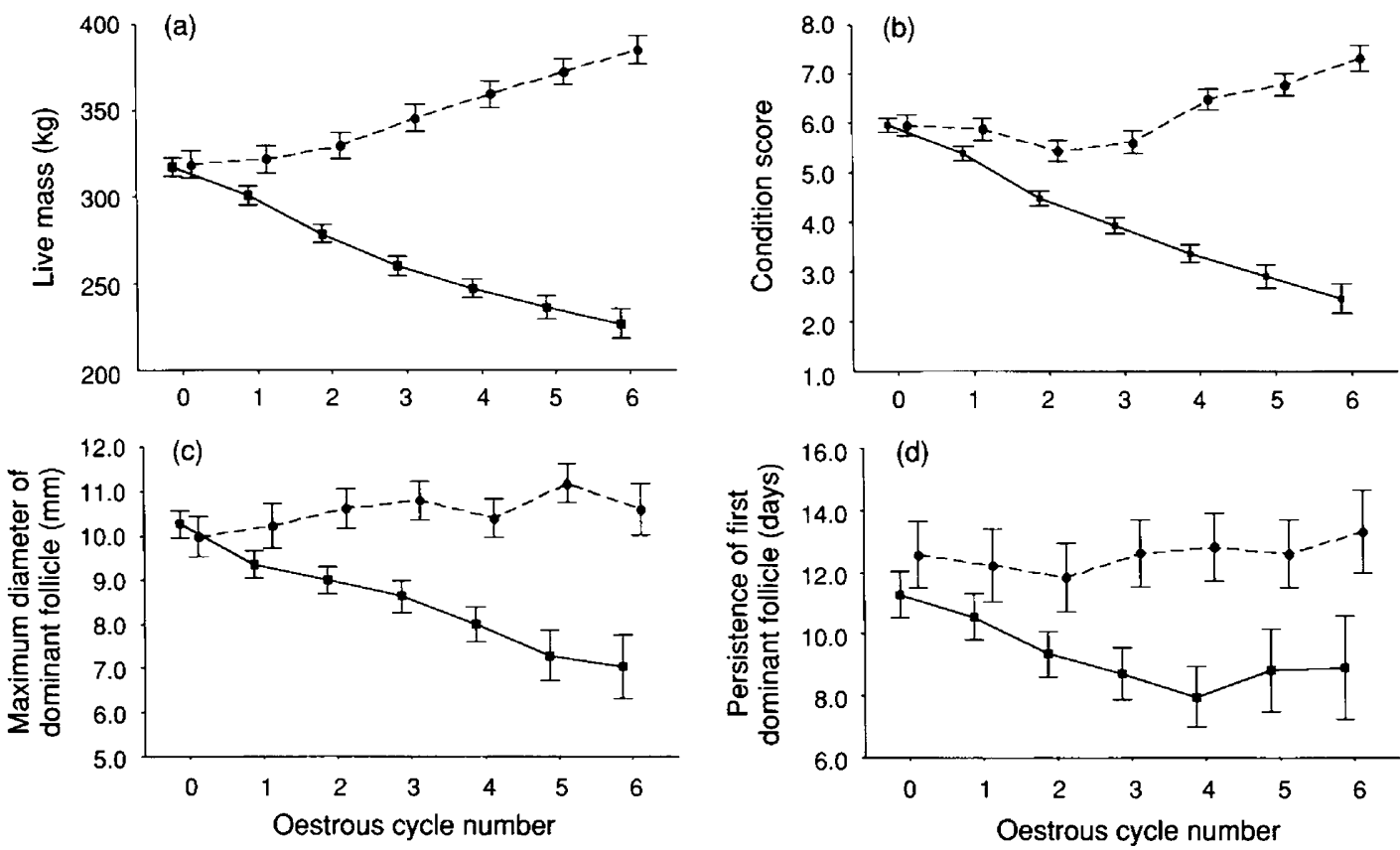

Fig. 1. Sequential changes in (a) live mass, (b) condition score, (c) maximum diameter and (d) persistence of the first dominant follicles of oestrous cycles in treated $(\bullet)$ heifers during the period of decreasing live mass and in control $(\bullet)$ heifers (least squares means \pm SEM). Data are included from individual animals only until the onset of anoestrus.
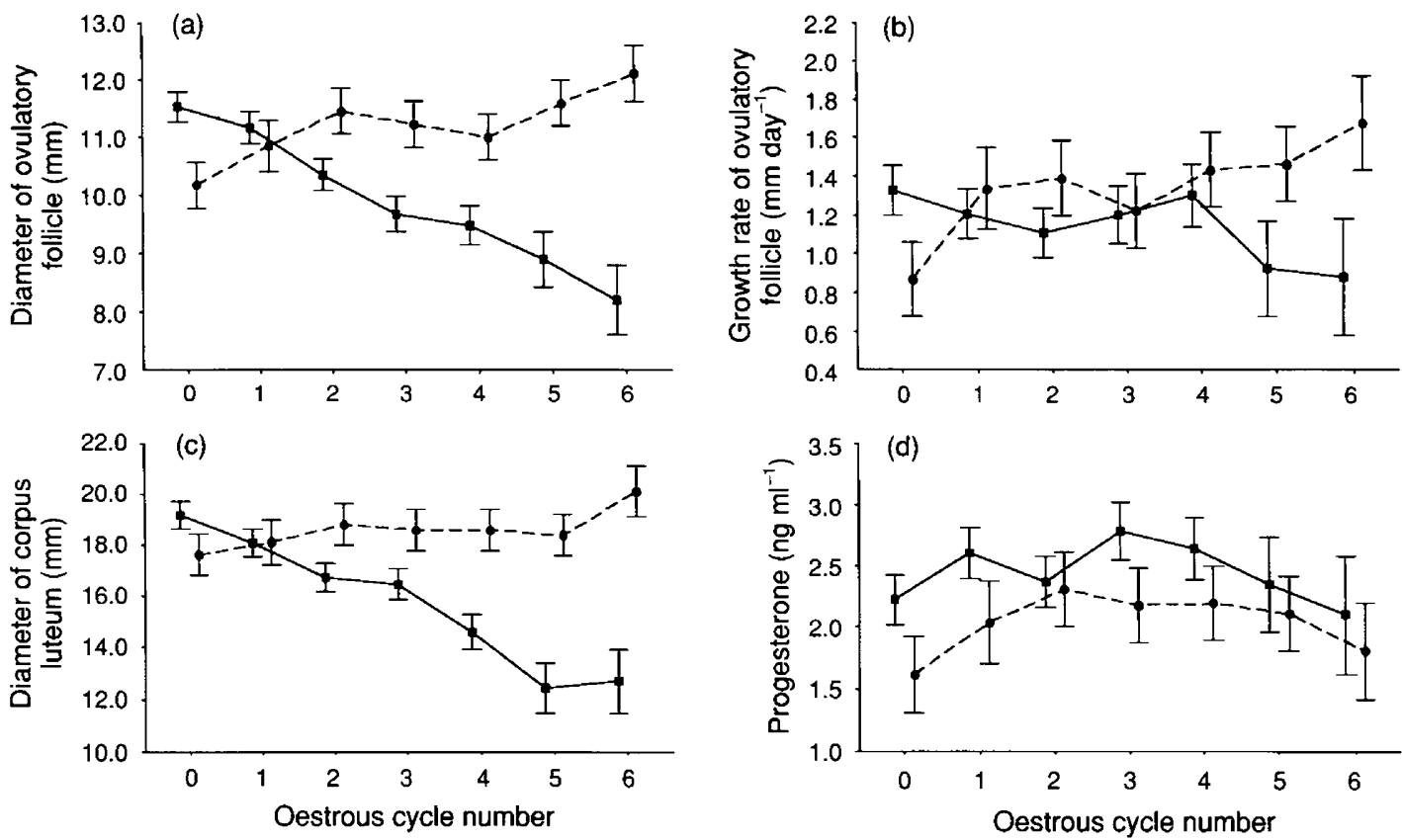

Fig. 2. Sequential changes in (a) ovulatory follicle size and (b) growth rate, (c) maximum diameter of corpora lutea and (d) mean concentration of progesterone in treated ( $\bullet$ ) heifers during the period of decreasing live mass and in control $(\bullet)$ heifers (least squares means \pm SEM). Data are included from individual animals only until the onset of anoestrus.

A decrease in live mass of $69.8 \pm 5.6 \mathrm{~kg}$, or $21.8 \pm 1.6 \%$ of initial mass, was required before the onset of anoestrus and occurred after $93.2 \pm 8.9$ days (Table 1). The diameters of final ovulatory follicles and corpora lutea before the onset of anoestrus were $83.3 \pm 3.9 \%$ and $76.3 \pm 3.1 \%$ of values before the initiation of dietary restriction, respectively (Table 2 ). The onset of anoestrus was best predicted by live mass $\left(\chi_{(1)}^{2}=4.37, P=0.04\right)$ and maximum diameter of corpora lutea $\left(\chi_{(1)}^{2}=4.19, P=0.04\right)$, when expressed as proportions of initial live mass and size of corpora lutea. The percentage decreases in live mass and maximum diameter of corpora lutea to give a $50 \%$ probability of anoestrus were $21.0 \%$ 
Table 1. Duration of period of decreasing live mass of Bos indicus heifers preceding the onset of anoestrus and period of increasing live mass to the resumption of ovulation in treated heifers, and the change in live mass during both periods and condition score at the end of each period

\begin{tabular}{|c|c|c|c|c|}
\hline \multirow[b]{2}{*}{ Parameter } & \multicolumn{2}{|c|}{ Decreasing live mass } & \multicolumn{2}{|c|}{ Increasing live mass } \\
\hline & Mean \pm SEM & Range & Mean \pm SEM & Range \\
\hline Duration (days) & $93.2 \pm 8.9$ & $48-132$ & $54.5 \pm 9.0$ & $8-97$ \\
\hline Change in live mass $(\mathrm{kg})^{\mathrm{a}}$ & $-69.8 \pm 5.6$ & $31-86$ & $71.9 \pm 11.1$ & $5-117$ \\
\hline Percentage change in live mass ${ }^{b}$ & $-21.8 \pm 1.6$ & $10-28$ & $22.7 \pm 3.6$ & $2-38$ \\
\hline Condition score & $3.3 \pm 0.19$ & $2.3-4.4$ & $3.9 \pm 0.3$ & $2.5-6.0$ \\
\hline
\end{tabular}

${ }^{a}$ Difference in live mass between beginning and end of periods.

bifference in live mass as a percentage of live mass before treatment.

Table 2. Ovarian characteristics at the onset of anoestrus in Bos indicus heifers expressed as percentages of values at the initiation of dietary restriction (mean \pm SEM)

Maximum diameter of first dominant follicle (mm)

Persistence of first dominant follicle (days)

Ovulatory follicle diameter $(\mathrm{mm})$

Growth rate of ovulatory follicle $\left(\mathrm{mm} \mathrm{day}^{-1}\right.$ )

Maximum diameter of corpus luteum ( $\mathrm{mm}$ )

\author{
$8.1 \pm 0.35(79.9 \pm 3.8)$ \\ $8.9 \pm 0.88(80.8 \pm 6.9)$ \\ $9.5 \pm 0.34(83.3 \pm 3.9)$ \\ $1.2 \pm 0.10(95.0 \pm 11.0)$ \\ $14.5 \pm 0.59(76.3 \pm 3.1)$
}

$(95 \%$ confidence interval $=(17.7,27.4))$ and $23.0 \%(16.7$, 37.0), respectively.

No differences were detected in the characteristics of $\mathrm{LH}$ secretion or in mean concentrations of FSH between groups over sampling periods 1 and $2(P>0.2$, Fig. 3$)$, although, at the time of the second sampling period treatment, heifers had lost $16.8 \pm 0.8 \%$ of initial live mass, maximum diameter of first dominant follicles of oestrous cycles had decreased by $12.2 \pm 3.7 \%$, ovulatory follicle size by $11.9 \pm 3.2 \%$ and maximum diameter of corpora lutea by $12.7 \pm 2.6 \%$. At the time of the third sampling period, no evidence of luteal activity was detected in treated heifers, as determined by ultrasonography or plasma concentrations of progesterone $\left(<0.2 \mathrm{ng} \mathrm{ml}^{-1}\right)$. However, no differences in the pulsatile secretion of $\mathrm{LH}$ or in concentrations of FSH were detected between periods 1 and $3(P>0.05$, Fig. 3). All control heifers continued to exhibit oestrous cycles of normal duration (19.4 \pm 0.68 days) throughout the experimental period.

\section{Period of increasing live mass}

After the initiation of feeding ad libitum diets to treatment heifers, subsequent to anoestrus, until resumption of ovulation, there were linear increases in live mass, maximum diameter, persistence and growth rate of dominant ovarian follicles with time $(P<0.001$, Fig. 4). The persistence of dominant follicles during this period (Fig. 4 d), in the absence of corpora lutea, was greater than the persistence of the first dominant follicle of oestrous cycles before the initiation of dietary restriction $(11.4 \pm 1.12$ days). Changes in follicle characteristics were linearly associated with changing live mass $(P<0.001)$, with a $10 \mathrm{~kg}$ increase in live mass resulting in an estimated $0.58 \pm$ $0.02 \mathrm{~mm}$ increase in maximum diameter, $0.10 \pm 0.001 \mathrm{~mm}$ day $^{-1}$ increase in growth rate and $1.1 \pm 0.05$ days increase in the persistence of dominant follicles.

Ovulation resumed after the emergence of $7.9 \pm 1.2$ follicles or after $54 \pm 9.0$ days. This period ranged from 8 to 97 days, with the condition score at resumption of ovulation varying from 2.5 to 6.0 (Table 1 ). There was no relationship between live mass of treated heifers at the beginning of the period of dietary restriction and time to onset of anoestrus $(P=0.20)$, but the duration of the interval to resumption of oestrous cycles was inversely related to the duration of decreasing live mass before anoestrus $\left(R^{2}=0.39, P=0.04\right.$, Fig. 5).

The duration of the first interovulatory interval following anoestrus was on average $9.36 \pm 1.43$ days, and was $\leq 8$ days in 8 of 11 heifers. The first ovulatory follicle was $105 \pm 4 \%$ of the size before the initiation of decreasing live mass; growth rate was $118 \pm 5 \%$ and a persistence was $98 \pm 9 \%$ of initial values. Live mass was $101 \pm 4 \%$ of mass at the start of dietary restriction. Short interovulatory intervals were followed by oestrous cycles of normal duration (19.9 \pm 0.48 days) in which, when compared with oestrous cycles before the initiation of decreasing live mass, there were no differences in ovarian characteristics $(P>0.1)$.

\section{Discussion}

Decreasing live mass in Bos indicus heifers was associated with linear reductions in the size of ovarian follicles and corpora 

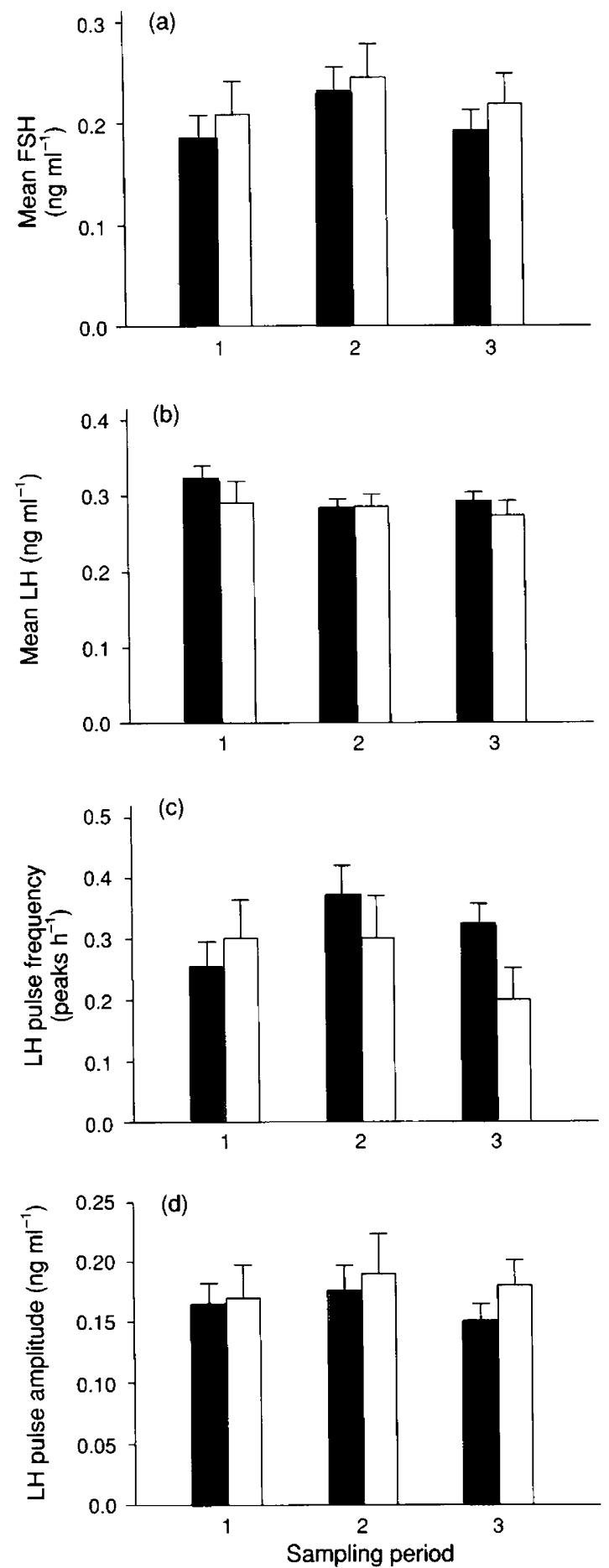

Fig. 3. Mean concentrations of (a) FSH and (b) LH, (c) LH pulse frequency and (d) pulse amplitude in treated ( $\square$ ) and control ( $\square$ ) heifers during the three periods of serial blood collection (least squares means \pm SEM). Period $I$ was before the start of dietary restriction; period 2 was when treated heifers had lost $17 \%$ of initial live mass; and period 3 was after the onset of anoestrus in treated heifers. For all characteristics, differences between groups from periods 1 to 2 , and from periods 1 to 3 were not significant $(P>0.05)$.

lutea, and in the persistence of the first dominant follicles of oestrous cycles. These ovarian changes were proportional to the percentage decrease in live mass. In the current study, a $10 \mathrm{~kg}$ reduction in live mass resulted in a decrease in ovarian follicular diameter of $0.3 \mathrm{~mm}$ and a decrease in persistence of 0.4 days. These changes are similar to those reported by Murphy et al. (1991) for two groups of Bos taurus heifers, in which a $38 \mathrm{~kg}$ difference in live mass resulted in a difference of $1.4 \mathrm{~mm}$ in maximum diameter and a 2.1 day difference in the persistence of dominant follicles. Similar findings were reported in prepubertal hiefers, when animals fed to gain $0.3 \mathrm{~kg}$ day ${ }^{-1}$ had smaller dominant follicles, at the same age, than did heifers fed to gain $0.9 \mathrm{~kg}$ day ${ }^{-1}$ (Bergfeld $e$ t al., 1994). In spite of the decrease in persistence of dominant follicles in the present study, there was no change in number of dominant follicles per oestrous cycle with decreasing live mass, in contrast to the findings of Murphy et al. (1991). The results reported here demonstrate that decreasing live mass results in gradual changes in ovarian follicular morphology, before the onset of nutritional anoestrus.

The effect of decreasing live mass on ovarian follicular function cannot be determined directly from the results of the present study. However, the ability of dominant follicles to ovulate following luteolysis and to form functional corpora lutea despite a decrease in size of $12 \%$, at the time of the second period of serial blood collection, suggests that granulosa cells could still respond normally to gonadotrophin stimulation. This finding is in agreement with studies on ewes (McNeilly et al., 1987), and postpartum cows (Ryan et al., 1994), in which the steroidogenic potential of follicular granulosa cells was not consistently related to body condition score when comparisons were made between follicles of equivalent status.

Although there was a significant decrease in the maximum diameter of corpora lutea with decreasing live mass, there did not appear to be any effect of decreasing mass on luteal function in the study reported here, as mean circulating concentrations of progesterone and the persistence of corpora lutea did not change with decreasing live mass. This finding is in contrast to previous reports of decreased peripheral concentrations of progesterone after reduction in live mass (Imakawa et al., 1983, 1986a), but is in agreement with other authors who found no difference in peripheral concentrations of progesterone in serum of animals losing or gaining mass (Harrison and Randel, 1986; Schrick et al., 1990; Murphy et al., 1991). An inverse relationship between level of nutrition and concentration of plasma progesterone in ewes is described by Parr et al. (1993) and attributed to differences in metabolic clearance rates, and may account for the absence of any decrease in peripheral concentrations of progesterone after reduction in live mass.

No differences were detected in the pulsatile secretion of $\mathrm{LH}$ and mean concentrations of FSH on day 6 after ovulation, between control and treatment groups, when treated heifers had lost $17 \%$ of live mass and the maximum diameters of follicles and corpora lutea had decreased by more than $10 \%$. It may be that, during the luteal phase of the oestrous cycle, changes in secretion of $\mathrm{LH}$ and FSH cannot be detected until a greater decrease in live mass has occurred. Richards et al. (1989) found a change in frequency of LH pulses in nutritionally restricted cows only after a $24 \%$ decrease in live mass. In the study reported here, sampling performed earlier in the luteal 
phase, when progesterone negative feedback on release of $\mathrm{LH}$ was low, or sampling during the follicular phase, may have revealed differences in pulsatile secretion of LH. In support of
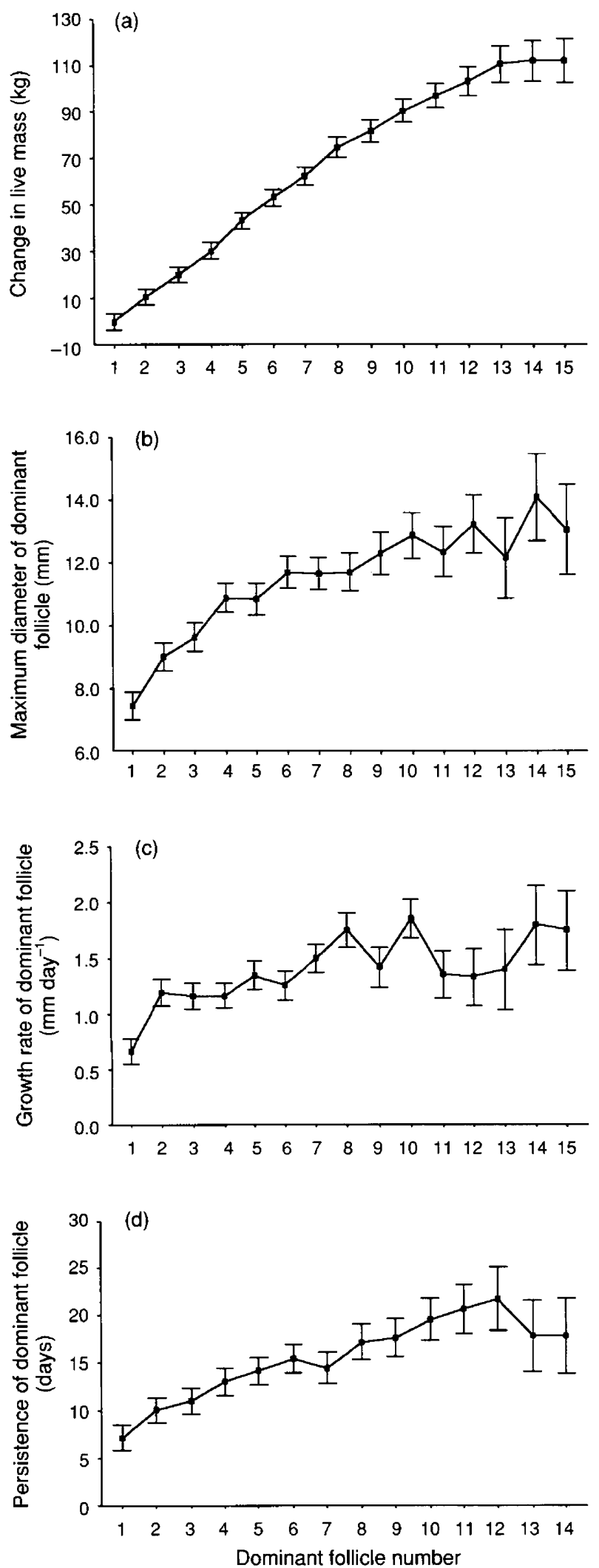

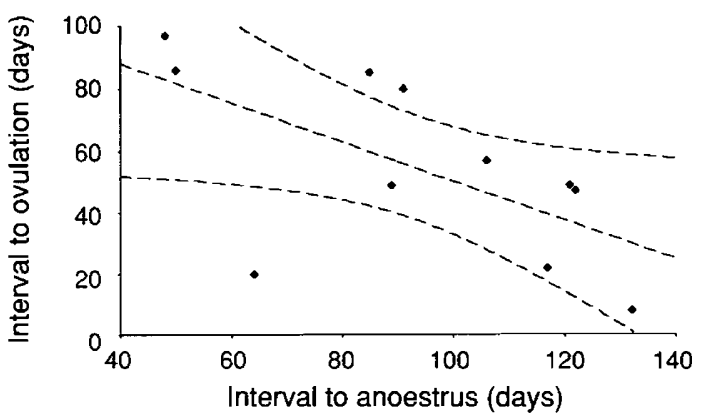

Fig. 5. Fitted linear regression, with $95 \%$ confidence intervals for the mean predicted response, of the interval to the resumption of oestrous cycles with the interval to the onset of anoestrus. Values for individual heifers are represented by different points.

this contention, secretion of $\mathrm{LH}$ remained low in treated heifers after the onset of anoestrus, when concentrations of progesterone were $<0.2 \mathrm{ng} \mathrm{ml}^{-1}$ and the frequency of pulses of $\mathrm{LH}$ would be expected to be high. This suggests that release of $\mathrm{LH}$ at this time was suppressed by the reduction in live mass.

Feeding unrestricted diets to heifers, following onset of anoestrus, resulted in a linear increase in ovarian follicular size and persistence with increasing live mass. Similar increased persistence of dominant follicles is reported in cattle treated with subluteal concentrations of progesterone and is associated with an increase in the frequency of LH pulses compared with control animals (Savio et al., 1993; Stock and Fortune, 1993). The increase in size and persistence in the study reported here were possibly a result of gradual increases in the frequency of LH pulses, as has been observed in nutritionally anoestrous heifers and prepubertal heifers after increased feed intake (Imakawa et al., 1986b; Kurz et al., 1990).

Resumption of ovulation in heifers after onset of anoestrus occurred when the mean maximum diameter and growth rate of dominant follicles were similar to those observed in ovulatory follicles before initiation of dietary restriction, and when mean live mass was $101 \%$ of initial live mass. Richards $e t$ al. (1989) reported that resumption of oestrous cycles following nutritional anoestrus occurred at $89 \%$ of initial live mass, when body condition score had increased to 4.6 from 3.5 at the time of anoestrus, and suggested that condition score dictates the initiation of oestrous cycles. However, in the study reported here, condition score at resumption of oestrous cycles varied from 2.5 to 6.0. The concept of a critical amount of body fat being required for ovulation has been largely discounted (Bronson and Manning, 1991); instead the availability of metabolic fuels is likely to be the mechanism linking nutritional status and reproductive function (Schillo, 1992). Although reproductive competence may be correlated with percentage of

Fig. 4. Sequential changes in (a) live mass, (b) maximum diameter, (c) growth rate and (d) persistence of dominant follicles in treated heifers during the period of unrestricted dietary intake after the onset of anoestrus (least squares means \pm SEM). The duration of the period displayed was 97 days and data are included for dominant follicles from individual animals only until the resumption of ovulation. The change in live mass is the cumulative increase in live mass after initiation of feeding ad libitum. 
body fat, it is not necessarily a causal relationship, as is indicated by the considerable variation in condition scores at the onset of anoestrus and resumption of ovulation in the current study. In addition, the characteristics of the first oestrous cycles of normal duration after anoestrus were similar to those of oestrous cycles before the initiation of dietary restriction, although the mean body condition score was only 3.9 , compared with 5.7 at the start of the experiment. However, no conclusions can be drawn from the current study as to the precise mechanisms responsible for the failure or resumption of ovulation after changes in live mass.

The first interovulatory interval was $\leq 8$ days in 8 of 11 heifers, similar to that in reports of shortened first oestrous cycles after postpartum anoestrus (Copelin et al., 1987), or in prepubertal heifers (Evans et al., 1994). Evans et al. (1994) suggested that dominant follicles giving rise to short-lived corpora lutea at puberty ovulate at a later stage of development than do ovulatory follicles in mature cattle. However, in the study reported here, the first ovulatory follicle after anoestrus had a similar persistence $(98 \%)$ and a greater rate of growth (118\%) compared with the ovulatory follicles before the initiation of dietary restriction, indicating that follicular development was not abnormal. Early luteolysis after the first ovulation in postpartum cows is caused by premature release of prostaglandin $\mathrm{F}_{2 \alpha}$ from the uterus, rather than impaired luteal function (Copelin et al., 1987). This early release is a consequence of increased concentrations of endometrial oxytocin receptors in animals with short luteal phases, resulting in increased responsiveness to oxytocin, which is responsible for stimulating release of prostaglandin $\mathrm{F}_{2 \alpha}$ (Garverick et al., 1992). However, it is not known whether a similar mechanism operates following nutritional anoestrus.

The duration of the period to resumption of ovulation after onset of anoestrus was inversely related to the time of decreasing live mass required to induce anoestrus, suggesting considerable between-animal variation in sensitivity to nutritional stress. Similar differences in susceptibility to dietary induced anoestrus were reported in rats fed $50 \%$ of normal intake (Knuth and Friesen, 1983). The variation in sensitivity of Bos indicus heifers may represent differences in priorities for energy allocation, with more sensitive animals having a better survival strategy for the harsh environmental conditions experienced in the dry tropics.

In conclusion, onset of nutritional anoestrus was preceded by linear decreases in the size of ovarian dominant follicles and corpora lutea, which were proportional to decreases in live mass. No changes in LH or FSH secretion on day 6 after ovulation were detected in treated heifers following a $17 \%$ decrease in live mass. This was probably due to the effect of progesterone negative feedback on $\mathrm{LH}$ secretion at this stage of the oestrous cycle, as characteristics of $\mathrm{LH}$ release were not altered in treated heifers after anoestrus, in the absence of any luteal activity, suggesting that release of $\mathrm{LH}$ at this time was suppressed by the reduction in live mass. After re-allocation to ad libitum diets, linear increases in the size and persistence of dominant follicles were observed until the resumption of ovulation, which occurred when dominant follicles attained maximum diameters similar to and growth rates slightly greater than those observed in ovulatory follicles before dietary restriction was initiated. Further investiga- tion is required into the mechanisms responsible for these morphological changes and their functional significance.

This study was partially funded by the Australian Meat Research Corporation. Reagents used in LH and FSH assays were kindly provided by D. Bolt (USDA Animal Hormone Program) and the NIDDK. The advice of J. E. Kinder and the assistance of C. Coleman, S. Stobart and J. Cave in data collection is gratefuly acknowledged.

\section{References}

Bergfeld EGM, Kojima FN, Cupp AS, Wehrman ME, Peter KE, Garcia-Winder M and Kinder JE (1994) Ovarian follicular development in prepubertal heifers is influenced by level of dietary energy intake Biology of Reproduction $\mathbf{5 1}$ 1051-1057

Bolt DJ and Rollins R (1983) Development and application of a radioimmunoassay for bovine follicle-stimulating hormone Journal of Animal Science 56 146-154

Bronson FH and Manning JM (1991) The energetic regulation of ovulation: a realistic role for body fat Biology of Reproduction 44 945-950

Collett D (1991) Modelling Binary Data Chapman and Hall, London

Copelin JP, Smith MF, Gaverick HA and Youngquist RS (1987) Effect of the uterus on subnormal luteal function in anoestrous beef cows Journal of Animal Science 64 1506-1511

Doogan VJ, Fordyce G, Shepherd RK, James TA and Holroyd RG (1991) The relationships between live mass, growth from weaning to mating and conception rate of Bos indicus cross heifers in the dry tropics of North Queensland Australian Journal of Experimental Agriculture 31 139-144

Evans ACO, Adams GP and Rawlings NC (1994) Endocrine and ovarian follicular changes leading up to the first ovulation in prepubertal heifers Journal of Reproduction and Fertility 100 187-194

Garverick HA, Zollers WG, Jr and Smith MF (1992) Mechanisms associated with corpus luteum lifespan in animals having normal or subnormal luteal function Animal Reproduction Science 28 111-124

Harrison LM and Randel RD (1986) Influence of insulin and energy intake on ovulation rate, luteinizing hormone and progesterone in beef heifers Joumal of Animal Science 63 1228-1235

Holroyd RG (1978) Methods of investigating beef cattle fertility. In Beef Cattle Production in the Tropics pp 233-246 Eds RM Murray and KW Entwistle. James Cook University of North Queensland, Townsville

Holroyd RG, O'Rourke PK and Allen PJ (1979) Reproductive performance of Shorthorn and Brahman crossbred cows in the dry tropics of north Queensland Australian Journal of Experimental Agriculture and Animal Husbandry 19 276-282

Imakawa K, Kittok RJ and Kinder JE (1983) The influence of dietary energy intake on progesterone concentrations in beef heifers Journal of Animal Science 56 454-459

Imakawa K, Day ML, Zalesky DD, Garcia-Winder M, Kittok RJ and Kinder JE (1986a) Influence of dietary-induced weight changes on serum luteinizing hormone, estrogen and progesterone in the bovine female Biology of Reproduction 35 377-384

Imakawa K, Day ML, Garcia-Winder M, Zalesky DD, Kittok RJ, Schanbacher BD and Kinder JE (1986b) Endocrine changes during restoration of estrous cycles following induction of anestrus by restriction of nutrient intake Journal of Animal Science 63 565-571

Jennrich RI and Schluchter MD (1986) Unbalanced repeated-measures models with structured covariance matrices Biometrics 42 805-820

Jolly PD (1992) Physiological and Nutritional Aspects of Postpartum Acyclicity in Bos indicus Cows. PhD thesis, James Cook University of North Queensland, Townsville

Knuth UA and Friesen HG (1983) Starvation induced anoestrus: effect of chronic food restriction on body weight, its influence on oestrous cycle and gonadotrophin secretion in rats Acta Endocrinologica 104 402-409

Kurz SG, Dyer RM, Hu Y, Wright MD and Day ML (1990) Regulation of luteinizing hormone secretion in prepubertal heifers fed an energy-deficient diet Biology of Reproduction 43 450-456

Lindsey JK (1993) Models for Repeated Measurements Clarendon Press, Oxford

McGinley R and Casey JH (1979) Analysis of progesterone in unextracted serum: a method using danazol [17 $\alpha$-pregn-4-en-20-yno(2,3-d) isoxazol-17-ol], a blocker of steroid binding to proteins Steroids 33 $127-138$ 
McNeilly AS, Jonassen JA and Rhind SM (1987) Reduced ovarian follicular development as a consequence of low body condition in ewes Acta Endocrinologica 115 75-83

NcNeilly JR, McNeilly AS, Walton JS and Cunningham FJ (1976) Development and application of a heterologous radioimmunoassay for ovine follicle-stimulating hormone Journal of Endocrinology 70 69-79

Merriam GR and Wachter KW (1982) Algorithms for the study of episodic hormone secretion American journal of Physiology 243 310-318

Murphy MG, Enright WJ, Crowe MA, McConnell K, Spicer LJ, Boland MP and Roche JF (1991) Effect of dietary intake on pattern of growth of dominant follicles during the oestrous cycle in beef heifers Journal of Reproduction and Fertility 92 333-338

Niswender GD, Reichert LE, Jr, Midgley AR, Jr and Nalbanov AV (1969) Radioimmunoassay for bovine and ovine luteinising hormone Endocrinology 84 1166-1173

O'Rourke PK, Doogan VJ, Robertson DJ and Cooke D (1991) Prediction of conception rate in extensive beef herds in north-western Australia. 2. Continuous mating and minimal management Australian Journal of Experimental Agriculture 31 9-14

Parr RA, Davis IF, Miles MA and Squires TJ (1993) Feed intake affects metabolic clearance rate of progesterone in sheep Research in Veterinary Science $\mathbf{5 5}$ 306-310

Richards MW, Wettemann RP and Schoenemann HM (1989) Nutritional anestrus in beef cows: body weight change, body condition, luteinizing hormone in serum and ovarian activity Journal of Animal Science 67 1520-1526
Ryan DP, Spoon RA, Griffith MK and Williams GL (1994) Ovarian follicular recruitment, granulosa cell steroidogenic potential and growth hormone/insulin-like growth factor-I relationships in suckled beef cows consuming high lipid diets: effects of graded differences in body condition maintained during the puerperium Domestic Animal Endocrinology 11 161-174

SAS (1992) SASISTAT Software: Changes and Enhancements, Release 6.07 SAS Institute Inc., Cary, NC

Savio JD, Keenan L, Boland MP and Roche JF (1988) Pattern of growth of dominant follicles during the oestrous cycle of heifers Journal of Reproduction and Fertility 83 663-67I

Savio JD, Thatcher WW, Badinga L, de la Sota RL and Wolfenson D (1993) Regulation of dominant follicle turnover during the oestrous cycle in cows Journal of Reproduction and Fertility 97 197-203

Schillo KK (1992) Effects of dietary energy on control of luteinizing hormone secretion in cattle and sheep Journal of Animal Science $\mathbf{7 0}$ 1271-1282

Schrick FN, Spitzer JC, Jenkins TC, Henricks DM and Althen TG (1990) Effect of dietary energy restriction on metabolic and endocrine responses during the estrous cycle of the suckled cow Joumal of Animal Science 68 3313-3321

SPSS (1993) SPSS Advanced Statistics, Release 6.0 SPSS Inc., Chicago IL

Stock AE and Fortune JE (1993) Ovarian follicular dominance in cattle: relationship between prolonged growth of the ovulatory follicle and endocrine parameters Endocrinology 132 1108-1114 